\title{
Monitoring Gas Metal Arc Welding Process by Using Audible Sound Signal
}

\author{
Jožef Horvat ${ }^{1}$ - Jurij Prezelj² - Ivan Polajnar ${ }^{2}$ - Mirko Čudina2,* \\ ${ }^{1}$ University of Ljubljana, College of Health Studies, Slovenia \\ 2 University of Ljubljana, Faculty of Mechanical Engineering, Slovenia
}

\begin{abstract}
The most frequently used arc welding process is gas metal arc welding (GMAW). Different methods are in use for monitoring the quality of a welding process. In this paper sound generated during the GMAW process is used for assessing and monitoring of the welding process and for prediction of welding process stability and quality. Theoretical and experimental analyses of the acoustic signals have shown that there are two main noise-generating mechanisms; the first is arc extinction and arc ignition having impulse character, the second is the arc itself acting as an ionization sound source. A new algorithm based on the measured welding current was established for the calculation of emitted sound during the welding process. The algorithm was verified for different welding condition, different welding materials and different specimen. The comparisons have shown that the calculated values are in good agreement with the measured values of sound signal.
\end{abstract}

(C)2011 Journal of Mechanical Engineering. All rights reserved.

Keywords: process monitoring, welding condition, sound emission, optimization process, weld quality

\section{INTRODUCTION}

The gas metal arc welding (GMAW) process is widely used because it is highly productive and cost effective. The process is suitable for robotization and mechanization. To maintain and direct the welding arc, an experienced welder uses their senses, especially eyes and ears to combine visual and audible information [1]. Unfortunately, during the GMAW process there are more high intensity side effects, such as heat, light and noise. At the same welding parameters audible A-weighted sound pressure level can rise above the daily permissible level of the welder's ear, $80 \mathrm{~dB}$. Measurements have shown that equivalent $\mathrm{A}$-weighted sound pressure level can even exceed $100 \mathrm{~dB}$ at the welder ear. On the other hand, the noise can be used for monitoring the quality of the welding process as well as for checking for anomalies in the welding process. The significance of sound in monitoring the arc welding processes has been known for a long time, but relatively few studies have been published in which sound waves are regarded as a source of information for monitoring the welding process.

Erdmann-Jesnitzer [2] and Jolly [3] published the first study on acoustic waves generated during the GMAW process. They found that sound waves are synchronized with short-circuiting and also discovered that the pressure of produced sound increases with the arc length and welding current. Much scientific work has been performed to verify the suitability of different arc signals for on-line monitoring. On-line quality control in automated welding operations is an important factor contributing to higher productivity, lower costs and greater reliability of the welded components. Arata [4] performed important measurements and concluded that the sound traveling into the sample and into the surrounding air has an influence on the welding process by affecting the behavior of molten pool. Sound waves generated by the arc excite the molten pool and cause its movement. Sound affects the welding process and its quality. Some attempts to use acoustic signals for on line monitoring of submerged arc welding were presented by Mayer, [5]. Rostek used computeraided acoustic pattern recognition to test the monitoring capabilities of acoustic signals, [6]. He observed the effect of operating parameters, such as voltage supply, feeding rate of consumable wire electrodes, stand off of contact pipe and flow rate of shielding gas on an arithmetic average of all frequencies amplitude and squared center 
of noise spectra gravity. He stated that within a wide range of the observed parameters there is a direct connection with the emitted noise. He also discovered that an unsuitable flow rate of shielding gas and its distribution, welding material dirtiness and non-uniformity of joint edge configuration have an effect on emitted noise. In 1994 a system for real-time analysis of weld quality in an arc welding process was patented [7]. The acoustic signals generated during the welding process are sampled and digitalized. The digitalized signals are transformed into frequency domain and then divided into a plurality of frequency bands. The average power for each frequency band is calculated and used as input to an artificial neural network for analysis of weld quality. A monitoring method using different statistic parameters to evaluate welding process stability was developed at the Faculty of Mechanical Engineering in Ljubljana [8] to [11]. Some authors believe that surrounding noise, which is not a result of the welding process, obstructs analysis of measured signals and might be considered as one of the most important obstacles for the acoustic monitoring technique, [4], [6] and [12]. From the available literature it can be seen that in the gas shielded arc-welding process, which most important parameters that have an influence on the emitted sound, are arc stability, metal transfer and oscillations of the molten pool. However, a deeper understanding of the relation between physical processes and the generation of sound is needed to overcome obstacles of pure statistical approach in the use of acoustic signals for on line monitoring. The present study is focused on establishing a theoretical and experimental base to implement acoustic monitoring of the welding processes in industrial environment. By a detailed analysis of each part of the acoustic signal, we tried to find the correlated sound source in time and space. Only investigations of audible sound (between 20 and $20000 \mathrm{~Hz}$ ) generated during GMAW in short circuiting mode are discussed in this paper.

\section{SOUND GENERATED DURING GAS METAL ARC WELDING PROCESS}

In the GMAW process an electric arc is established between consumable wire electrodes and a melted zone on the welding material. Both are shielded by gas in the form of active $\mathrm{CO}_{2}$ or gas mixtures containing $\mathrm{Ar}, \mathrm{CO}_{2}$, etc. The power source usually has a constant static voltage characteristic of $U=f(I)=$ const. At constant adding velocity of consumable electrode the result is a stabile arc length. This phenomenon is known as the principle of internal self-regulation, [13] and [14]. Different phases of material transfer during the GMAW process, in short circuit mode and in dependence on the arc formation are also depicted in this works. The corresponding welding current is presented in Fig. 1.

At points 1 to 3 in Fig. 1 there is no arc, whereas at points 4 to 6 an arc is formed. In points 1 to 3 and towards point 4 a consumable electrode is in contact with the molten pool; this period of short circuit is depicted as a welding current peak.

As accompanying phenomena during the GMAW process, more different sound sources appear simultaneously and/or successively. They have different characteristics and they differ in time and form of appearance. With regards to time, there are two characteristic time intervals of noise generation. The first is the short circuit that ends with arc ignition (see points 1 to 4 in Fig. 1) and the second is the oscillations of the burning arc that ends with arc extinction (points 4 to 6 and 1 in Fig. 1).

Emitted sound can be classified in the two main groups. One appears in the form of sound impulse and the other appears in the form of smallchangeable broadband or so-called "turbulent" noise. The term is used from machinery noise. The sound impulse is connected with the rapid current changes and has two origins. The first origin is the result of short-circuiting between the electrode and welding material, and arc extinction thereof, which is accompanied by partial spraying of the molten drop when it strikes the molten pool (see point 1 in Fig. 1). The second origin of sound impulse is the result of tearing off the molten drop from the welding electrode and sudden arc ignition (spark ignition) which causes a rapid increase in temperature and expansion of shielding gas around the arc, causing a strong pressure pulsation in the surrounding air, (see time 4 in Fig. 1).

The "turbulent" noise is the result of many processes and mechanisms that generate sound or have influence on sound wave propagation. Among them the oscillation of the arc, the 


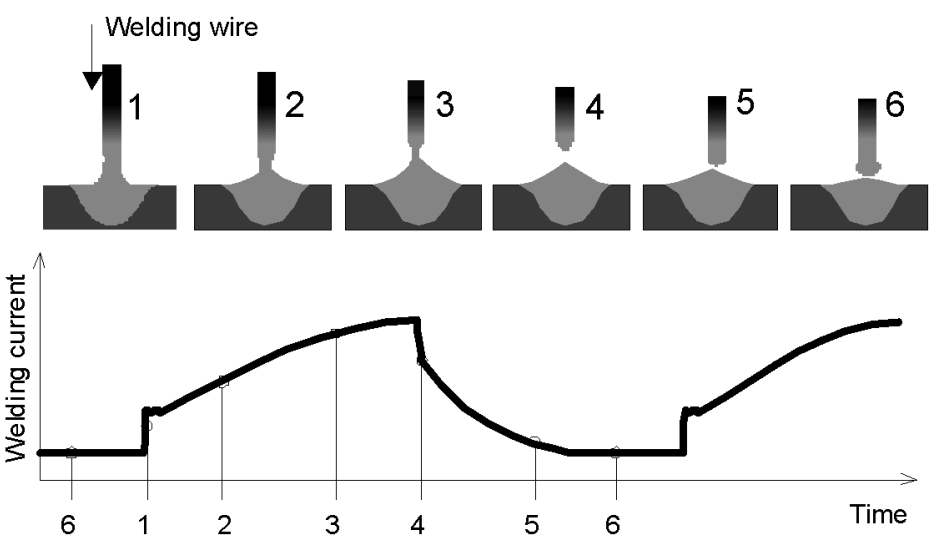

Fig. 1. Description of different phases of material transfer during GMAW in short circuit

electrode and the molten pool, as well as racking of the materials due to inner tension relaxation are the most important. Others can be neglected, either due to their small contribution to the acoustic signal or due to their appearance out of the audible frequency range.

In industrial environment, a background noise caused by secondary sources and reverberation (parasitic) noise cased by reflection are presented. In this case, the sound impulse as well as the turbulent noise are additionally influenced and contaminated, and even overlapped by background noise. To check the effect of background noise, the sound pressure levels with and without a welding process have to be measured. If the difference between them is higher than $10 \mathrm{~dB}(\mathrm{~A})$, the effect of the background noise is negligible. On the other hand, if background noise is equal or higher than the common level of noise, then the noise due to welding process is negligible and measurement of the welding noise is not valid. In special cases the background noise can be extracted by filters.

The presented measurements have shown that the impulse noise generated during the arc ignition (point 4 in Fig. 1) is the most dominant noise source during the welding process. In principle, sound impulse involves acoustic transient phenomena. The core of the ignition spark is heated up to $24,000 \mathrm{~K}$, and expansion speed of the shock wave is over $1000 \mathrm{~m} / \mathrm{s}$. As a consequence of rapid increase of temperature, a strong pressure oscillation appears which causes the sound impulse.
Some authors tried to find a correlation between the emitted sound pressure and the arc volume, while other studies have revealed that amplitude of sound pressure $p(t)[\mathrm{Pa}]$ is correlated to the arc voltage supply $(U),[16]$, or to the electrical power (UI) supplied to the arc, [17] and [18]:

$$
p(t)=C_{1} \frac{d}{d t}[U(t) \cdot I(t)],
$$

where $C_{1}$ is the factor of proportionality, which, for a spherical wave propagation, depends on geometrical factor $\alpha$, on adiabatic expansion coefficient $\kappa$, and on speed of sound in the arc $c$ $[\mathrm{m} / \mathrm{s}]$ by [18]:

$$
C_{1}=\alpha \frac{\kappa-1}{c^{2}} .
$$

The geometrical factor $\alpha$ depends on microphone position relative to the arc $r$ (see Fig. 2): $\alpha=1 / r\left[\mathrm{~m}^{-1}\right]$. The speed of sound in the arc $\mathrm{c}$ is changing during the process and represents a non-linearity. In the case of the three phase arc furnace, the current in each phase must be compared with the wave form of the total sound emitted by the furnace. Such a comparison reveals which of the three arcs needs to be adjusted and therefore, which electrode has to be lowered or raised in the furnace [16].

The voltage supply $U(t)$ in Eq. (1) is defined by electrical circuit. The electrical circuit of the welding appliance (power supply, cable, consumable wire, arc and welding material) consists of the basic elements: resistance $R[\Omega]$, 
inductance $L[\mathrm{H}]$ and capacitance $C[\mathrm{~F}]$. A suitable equation for describing the electrical circuit can be obtained by using the Ohm's and Kirchoff's law:

$$
U(t)=R I(t)+L \frac{d I(t)}{d t}+\frac{R_{a} I(t)}{1+j \omega C_{a} R_{a}},
$$

where $I(t)$ is time dependent the electric current [A], $U$ is the equivalent open-circuit voltage supply [V] usually of constant value, $R_{\mathrm{a}}$ and $C_{\mathrm{a}}$ are the resistance and capacitance of the arc $\omega$ is the angular frequency $\left[\mathrm{s}^{-1}\right]$. Since the arc is responsible for noise generation can be expressed the arc voltage $U_{\mathrm{a}}$ explicitly, similarly to Choi [19]:

$$
U_{a}=R_{a} I=U-U_{R}+U_{L}=U-R I-L \dot{I} .
$$

By substituting Eq. (4) into Eq. (1) and after making time derivation the next equation follows:

$$
\begin{aligned}
p(t) & \left.=C_{1} \frac{d}{d t}[(U-R I-L \dot{I}) I)\right]= \\
& =C_{1}[U \dot{I}-2 R I \dot{I}-L(\dot{I}+I \ddot{I})],
\end{aligned}
$$

where $\dot{I}$ is derivation of the current $\left[\mathrm{A} \cdot \mathrm{s}^{-1}\right]$ and $\ddot{I}$ is second derivation of the current $\left[\mathrm{A} \cdot \mathrm{s}^{-2}\right]$. Eq. (5) is a transfer function between the welding current $(I)$ as an input into the welding process and emitted sound pressure $p(t)$ as an output from the welding process. The transfer function, which depends on the voltage supply and welding current, the current first and second derivation, allows us to compare the welding current with the generated sound pressure.

\section{MEASUREMENT SETUP}

Experiments were performed using an experimental set-up shown in Fig. 2. Standard industrial welding equipment was used in the experiments. As power supply an ISKRA E-450 with constant static voltage characteristics was used, the consumable wire was electrode VAC $60(\varphi=1.2 \mathrm{~mm}$ with $1.5 \% \mathrm{Mn}, 0.9 \% \mathrm{Si}$ and $0.1 \% \mathrm{C}$ ), and the shielding gas mixture was CORGON $\left(82 \% \mathrm{Ar}\right.$ and $18 \% \mathrm{CO}_{2}$, with flow rate $Q=9 \mathrm{l} / \mathrm{min}$ ). Measurements were performed in the short circuit mode of operation, as it is widely used in industrial environment. Two different materials were used in the experiment, heated steel (with $0.4 \% \mathrm{C}, 0.65 \% \mathrm{Mn}, 0.045 \% \mathrm{~S}_{\max }$ and $\left.0,045 \% \mathrm{P}_{\max }\right)$ with a thickness of the specimen 6 $\mathrm{mm}$ and structural steel (with $0.1 \% \mathrm{C}, 0.45 \% \mathrm{Mn}$, 0.03 Smax and $0.03 \%$ Pmax) with a thickness of the specimen $12 \mathrm{~mm}$. The welding current ranged from 120 to $135 \mathrm{~A}$ and the speed of welding was $40 \mathrm{~mm} / \mathrm{s}$, whereas the voltage supply was approximately constant $\left(\mathrm{U}_{1}=21 \mathrm{~V}\right)$.

An A/D converter with a sampling rate of $48 \mathrm{kHz}$ per channel and with 16-bit data resolution was used for data acquisition. Twenty seconds of the welding process were recorded for each

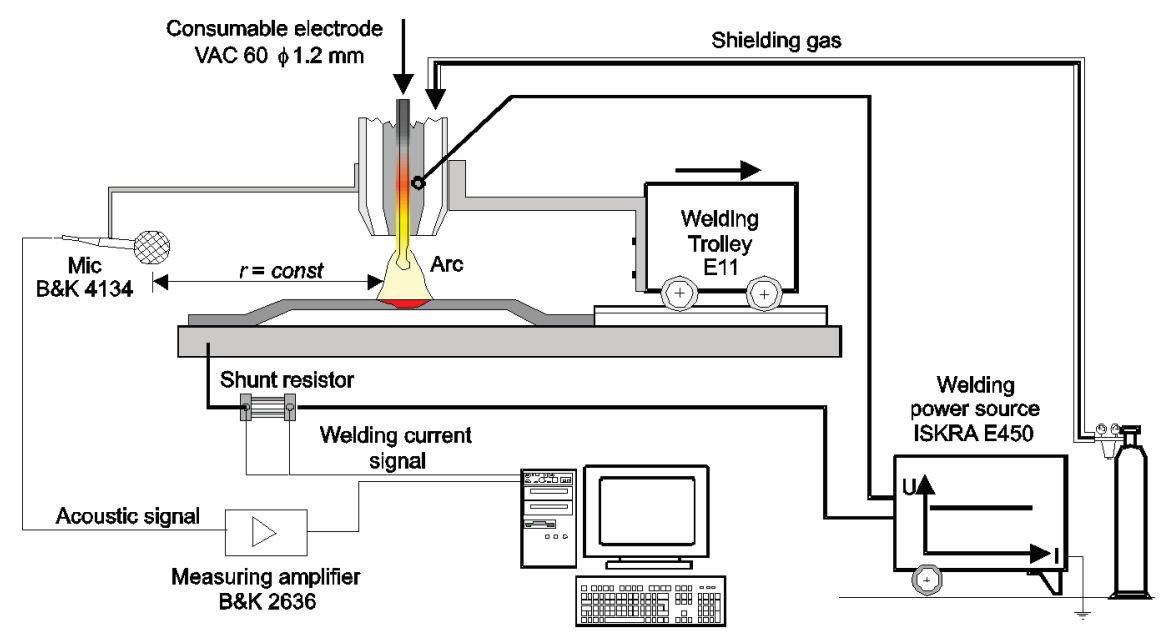

Fig. 2. Experimental set-up of the GMAW process 
single environment, and stored on hard disk. The welding current was measured via a shunt resistor. A half-inch Bruel\&Kjear, type 4134 condenser microphone was fixed to the welding head on a distance of $L=0.35 \mathrm{~m}$ from the arc in order to maintain constant distance from the welding process. This distance is approximately equal to the distance of the welder's head from the arc, which means that the measured signal of noise can also be used for assessing the effect of welding noise on the welder.

\section{EXPERIMENTAL RESULTS AND DISCUSSION}

In Fig. 3 the measured welding current (a) and sound pressure signal (b) during the GMAW process with regards to time are presented. The welding current signal consists of peaks, which are connected with short circuits. The sound signal consists of short impulses separated by long-term "turbulent" noise; see also Fig. 4. There are two different sound impulses and they are in correlation with the welding current peak. The first appears at the moment of short circuit arc extinction (smaller inexpressive one) and the other appears at the moment of arc ignition (the most powerful one). This means that greater sudden changes of the current cause higher level of sound impulse.
Analyses of the measured results have shown that amplitudes of the sound impulses generated during short circuit arc extinction depend on the sorts of shielding gas and structure of welded material used. Alternatively, the amplitude of the sound impulses generated during arc ignition also depends on the energy input during the welding current peak. The first impulse (smaller one) can be neglected in comparison to the second larger one. The larger impulse, occurring at the end of the welding current peak, can thus be assigned to the corresponding welding current peak, see Figs. 3 and 4. From sound signal analyses it follows that between two sound impulse peaks due to arc extinction and arc ignition, under the welding current peak, the sound signal consists of just low-level background noise (denoted by background noise in Fig. 4).

The sound signal between two successive impulses, which is between two welding current peaks, consists of turbulent noise, generated mostly by pulsation of the shielding gas in the arc (denoted by "turbulent" noise in Fig. 4). It has much higher level than the background noise. The audible sound after welding during cooling is of the turbulent character, but of a much lower level than during the welding process and therefore not important for the welder and the total emitted noise. This denotes that the welding sound is generated and dominated by the arc itself, as already stated by many authors, [16] and [18] The

a)

)

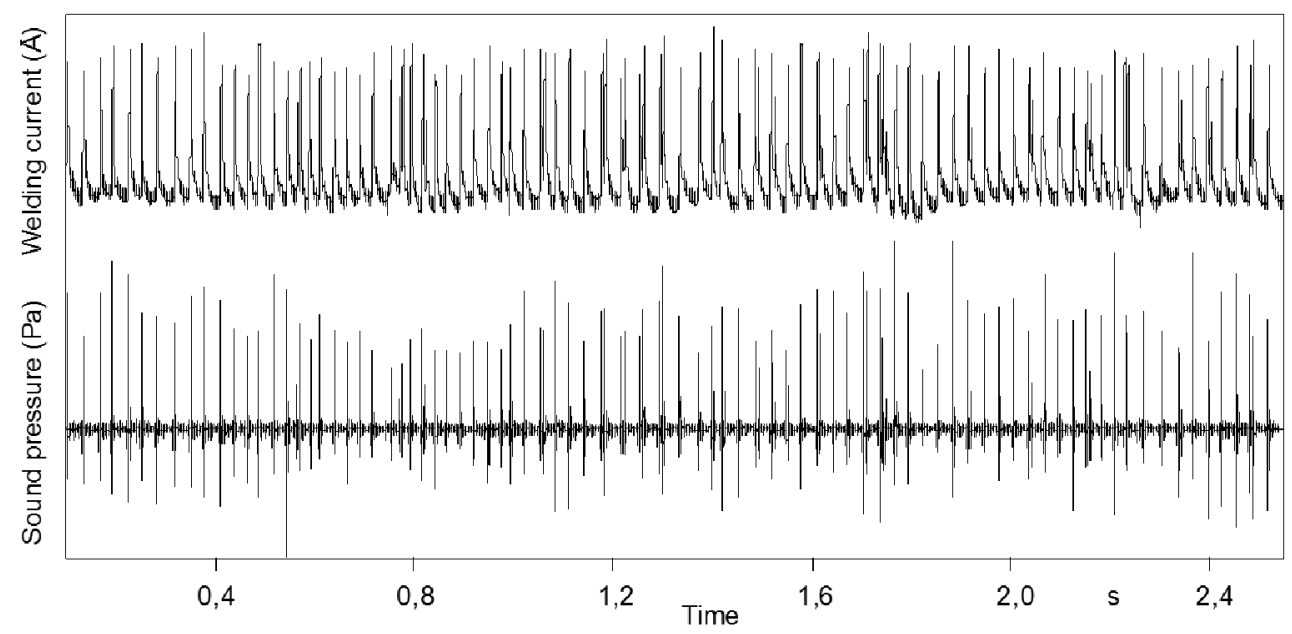

Fig. 3. a) measured welding current, b) acoustic signal during GMAW process for heatted steel 
turbulent arc noise appears in a high frequency range above $5 \mathrm{kHz}$, see Fig. 5 .

In Fig. 5 spectra of four successive sound impulses are presented. Each of them corresponds to the particular welding current peak. The third successive impulse has a much lower level of sound then the others, which means that, in this case, the welding process was incomplete (defective). However, the sound pulse after it (fourth in Fig. 5) has a much more pronounced level, which means that the energy from the incompletely developed welding process is transferred to the following one. The higher level of turbulent arc noise is a consequence of lagging behind energy from the previous pulse and dissipation of energy (see framed part of the spectrogram in Fig. 5). Sound spectra amplitude of impulses can thus be used for on-line control of some parameters, as for example, volume of the molten material and therefore for control of welding process stability and quality [9].

From Fig. 5 it can be seen that the frequency spectra of the turbulent arc noise is pronounced above 5 and $7 \mathrm{kHz}$, respectively,

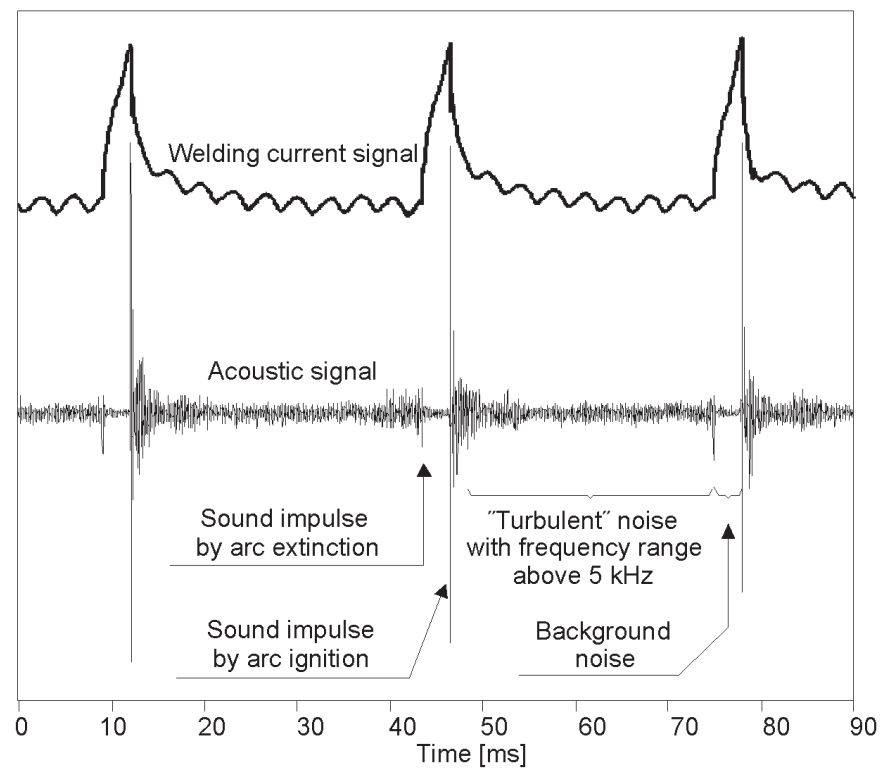

Fig. 4. Three successive welding current peaks with corresponding sound impulses for heated steel

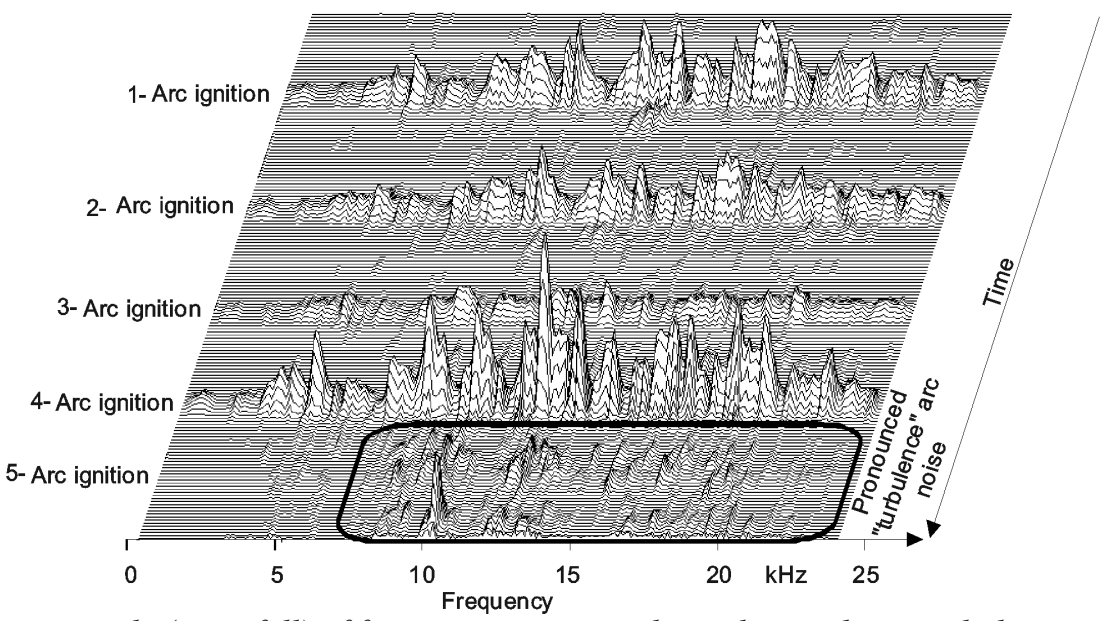

Fig. 5. Spectra cascade (waterfall) of four successive sound impulses with arc turbulent noise for heated steel 
whereas the frequency spectra of the sound impulses prevails above 3 and $5 \mathrm{kHz}$, respectively, with some pronounced peaks in the frequency range between 8 and $16 \mathrm{kHz}$.

In order to check the relative importance of the turbulent arc noise in comparison with the impulse noise the sound pressure level $L_{p}$ [dB] was used. For this purpose the following equation was used:

$$
L_{p}=20 \log p / p_{o},
$$

where $p$ is the RMS value of sound pressure [Pa] and $p_{o}$ is the reference sound pressure, $2 \cdot 10^{-5} \mathrm{~Pa}$. For assessment of human perception of noise A-weighted sound pressure level $[\mathrm{dB}(\mathrm{A})]$ is commonly used. Detailed analyses have shown that the total level of welding noise is 91.5
$\mathrm{dB}(\mathrm{A})$ and that of turbulent noise alone is 81.0 $\mathrm{dB}(\mathrm{A})$. The impulse noise is up to $10 \mathrm{~dB}(\mathrm{~A})$ and higher than the turbulent arc noise, wich means that the contribution of the turbulent arc noise is negligible. This means that the impulse noise can represent the total emitted noise, [20] to [22].

\section{NUMERICAL ANALYSIS}

Eq. (5) was used for the calculation of the emitted sound pressure generated by the GMAW process. It is based on the measured welding current data only. Values of the constants in Eq. (5), resistance $R$, inductance $L$ and capacitance $C$, were determined by comparison of the calculated and measured values of the sound pressure using the least mean square (LMS) method. The value
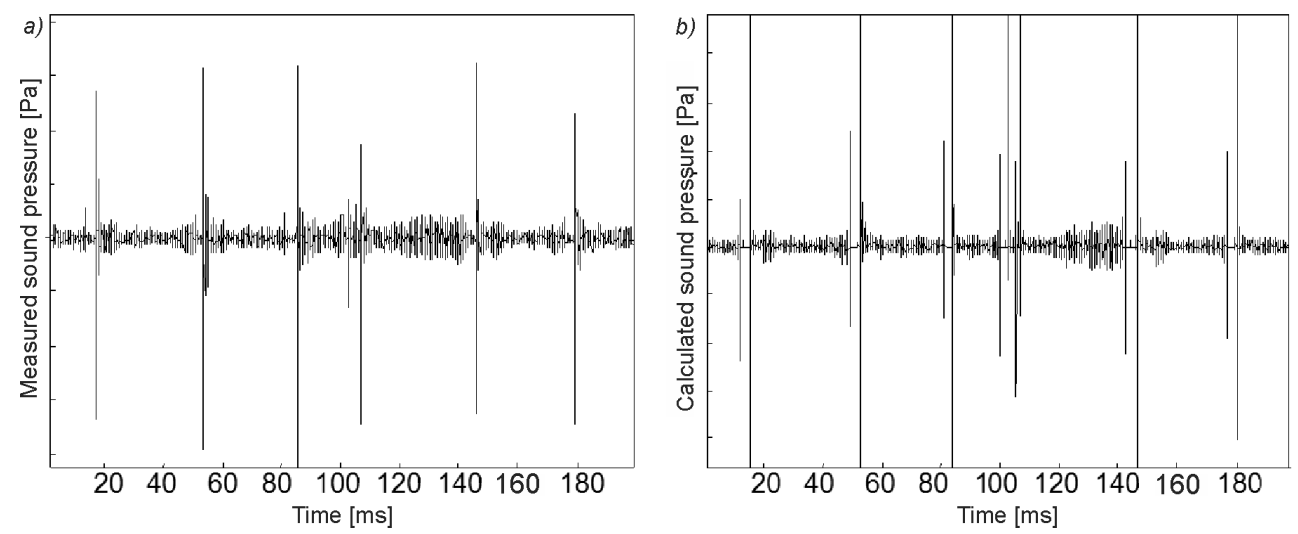

Fig. 6. a) Measured acoustic signal of the stable welding process and b) calculated acoustic signal from measured welding current using Eq. (5) for heated steel
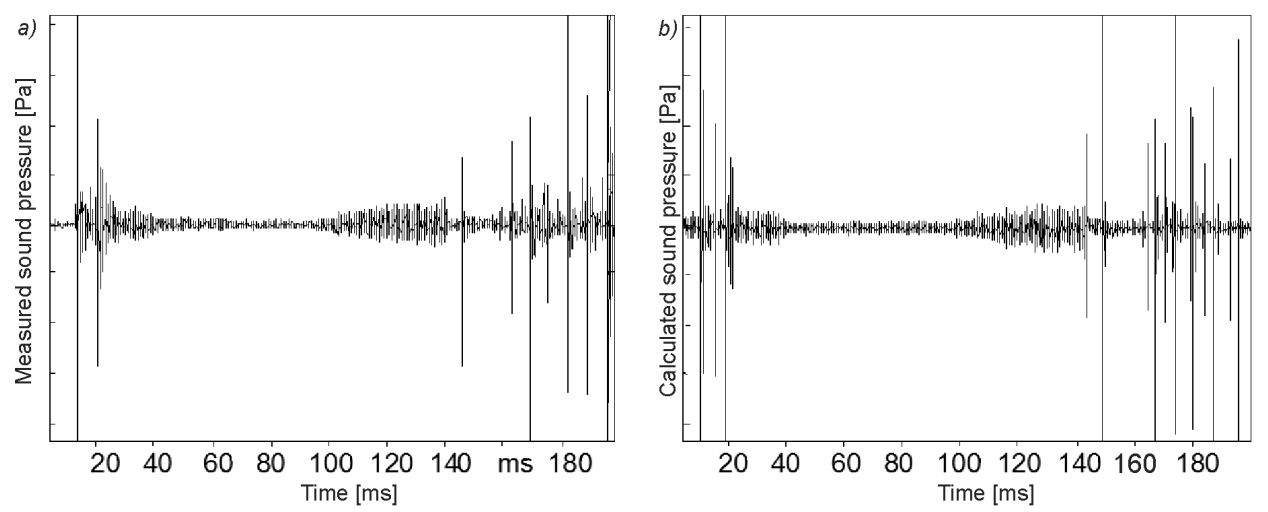

Fig. 7. a) Measured acoustic signal of the welding process initialization and b) calculated acoustic signal from the measured welding current using Eq. (5) for structural steel 
of the constants (resistance $R$, inductance $L$ and capacitance $C$ ) are changing over a longer time scale during stabile welding, due to instability in the welding process, but detailed analyses have shown that these values $(R, L, C)$, as well as the constant of proportionality $C_{1}$ in Eq. (5), can be treated as constant values for the calculation of impulse sound. Using the average value of the constants, the emitted sound pressure was calculated and compared with the measured acoustic signal.

Figs. 6 and 7 show the comparison between calculated and measured acoustic signals. Agreement between calculated and measured results is especially good for the arc burning process in the period between two successive noise impulses; whereas the calculated value of the sound impulses is higher than the measured one, although the sound impulses appear at the same positions as the measured signal, see Figs.
6 and 7. Some of the results have already been published by [23]:

Detailed analyses have shown that the values of resistance $R$, inductance $L$ and capacitance $C$ in Eq. (5) can be treated as constant values for calculation of turbulent and impulse sound, whereas the constant of proportionality $C_{1}$ is not the same for turbulent arc noise and for the sound impulse. The value of the constant $C_{1}$ is smaller for the impulse noise. The reason for this is sound non-linearity at the time of sound impulse. The coefficient $C_{1}$ represents, thus, a measure of non-linearity. Using a smaller value of the constant $C_{1}$ in Eq. (5), which is appropriate for the calculation of the sound impulse, reduces the level of the calculated turbulent noise. A comparison between the measured and calculated values by using of Eq. (5) for four successive sound impulses is presented in Fig. 8 for heated steel. Agreement between the calculated values
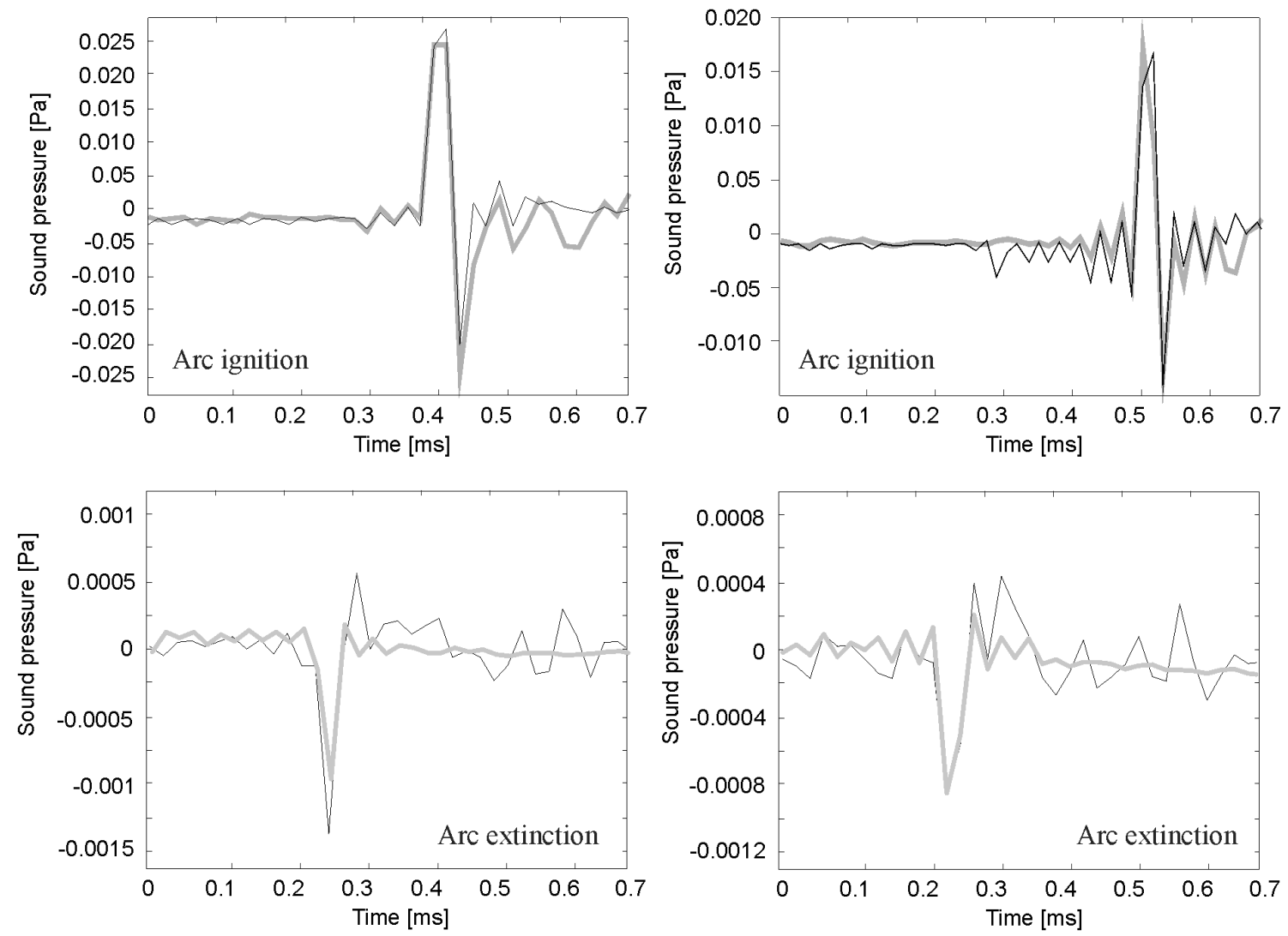

Fig. 8. Comparison between measured values of four successive sound impulses from Fig. $3 b$ (thin curve) and Calculated values from welding current using Eq. (5) (thick curve) for heated steel 

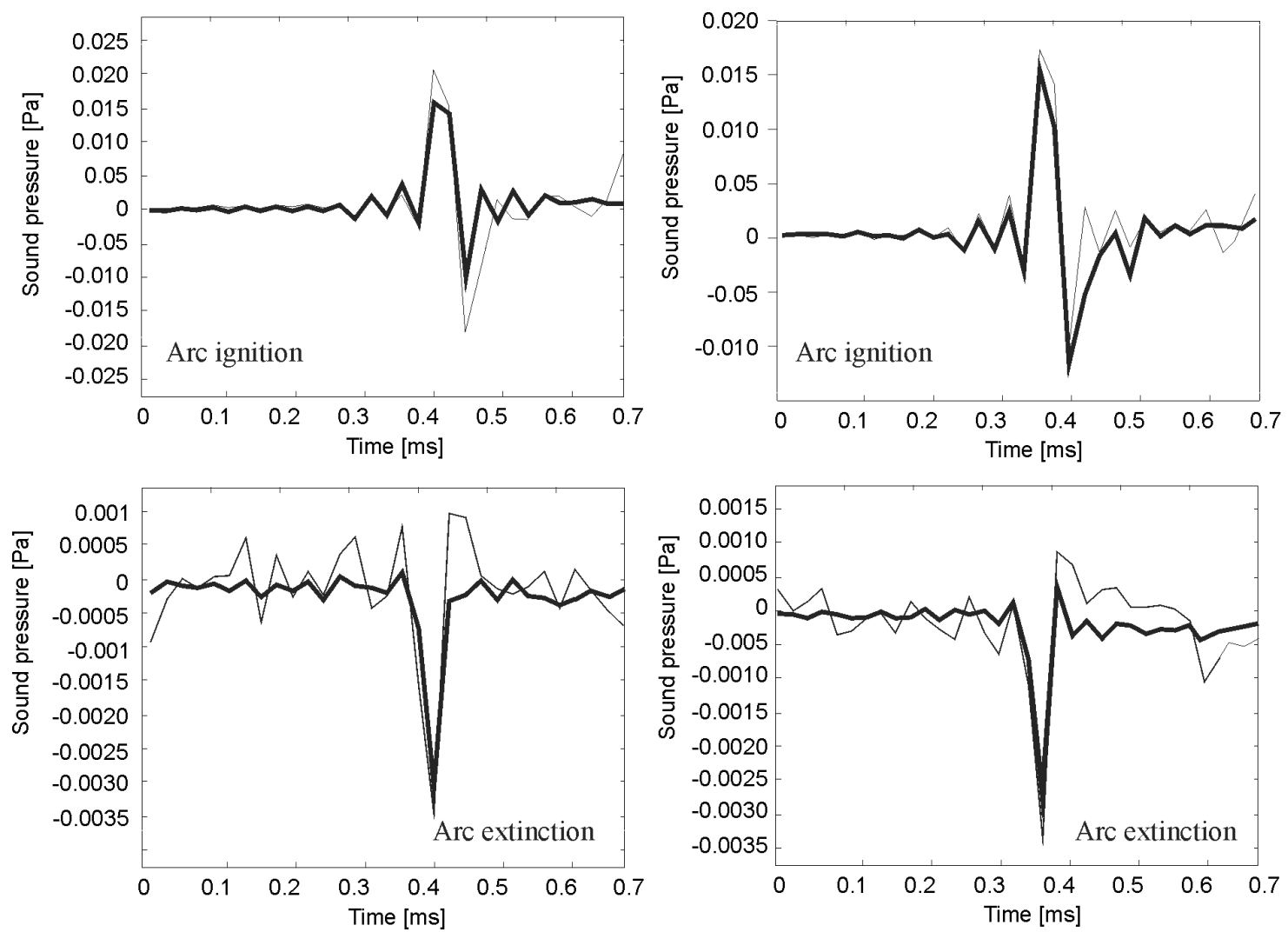

Fig. 9. Comparison between measured values of four successive noise impulses from Fig. 11 (thin curve) and calculated values from welding current using Eq. (5) (thick curve) for structural steel

(thick curve) and measured values (thin curve) is quite good. The small differences between the measured and calculated noise after the occurrence of impulses can also be assigned to the effect of reverberation noise from the surrounding room walls. The greater differences between the measured and calculated values for arc extinction can be neglected since the sound pressure of the impulse due to arc extinction is much lower than the noise of the arc ignition, see scale in Fig. 8 and impulse at the arc extinction in Fig. 4. Similar results were obtained for structural steel, see Fig. 9.

Since the total A-weighted sound pressure level of impulses is far more than $10 \mathrm{~dB}(\mathrm{~A})$ higher then the corresponding total level of the turbulent arc noise and even higher than the A-weighted total sound pressure level including the impulse and turbulent arc noise (see also Fig. 5) it can be said that the level of impulse noise also represents the total emitted noise of the welding process. The proposed algorithm, Eq. (5), with constant $C_{1}$ for calculation of impulse noise can, thus, be used for calculation of the total noise level generated by the GMAW process. It can also be used for online monitoring and control of stability and quality of the welding process. Fig. 10 shows an inclined plate specimen of heated steel with a defect in the welding process and Fig. 11 shows a flat specimen of structural steel with a defect in the welding process in the enlarged scale, which is noticed in the welding current and sound pressure records.

The inclination of the plate specimen in Fig. 10 causes change in the torch-to-work distance as welding progresses (in this case, the distance becomes increasingly smaller) and consequently, change in the process parameters, which can result in the observed defect. Detailed analyses have shown that the observed defect is not the result of the inclination (which is relatively small, less then $2.5 \%$ ), but the result of anomalies in the welding process, possibly due to dirtiness or 
erratic wire feed. Similar defects have also been observed on a flat plate specimen. The variation in the welding current corresponded to sound pressure records. Fig. 11 shows the point where the defect occurred (enlarged scale). The sound pressure record can also be used to calculate the

Table 1: Characteristic noise levels at measuring parameters: current $I=180 \mathrm{~A}$, voltage $U=21 \mathrm{~V}$ and feeding rate of consumable wire electrode $v=11 \mathrm{~m} / \mathrm{min}$.

\begin{tabular}{|c|c|c|c|}
\hline $\begin{array}{c}\text { Mic. distance } L \\
\text { in Fig. } 2[\mathrm{~m}]\end{array}$ & $\begin{array}{c}\text { Peak noise } L_{\text {Apk(MaxP) }} \\
{[\mathrm{dB}(\mathrm{A})]}\end{array}$ & $\begin{array}{c}\text { Equivalent sound pressure } \\
\text { level, } L_{\text {Aeq }}[\mathrm{dB}(\mathrm{A})]\end{array}$ & $\begin{array}{c}\text { Impulse noise } L_{\text {Aim }} \\
{[\mathrm{dB}(\mathrm{A})]}\end{array}$ \\
\hline 1.5 & 127 & 89 & 91 \\
\hline 1 & 127 & 93 & 95 \\
\hline 0.3 & 128 & 98 & 100 \\
\hline
\end{tabular}
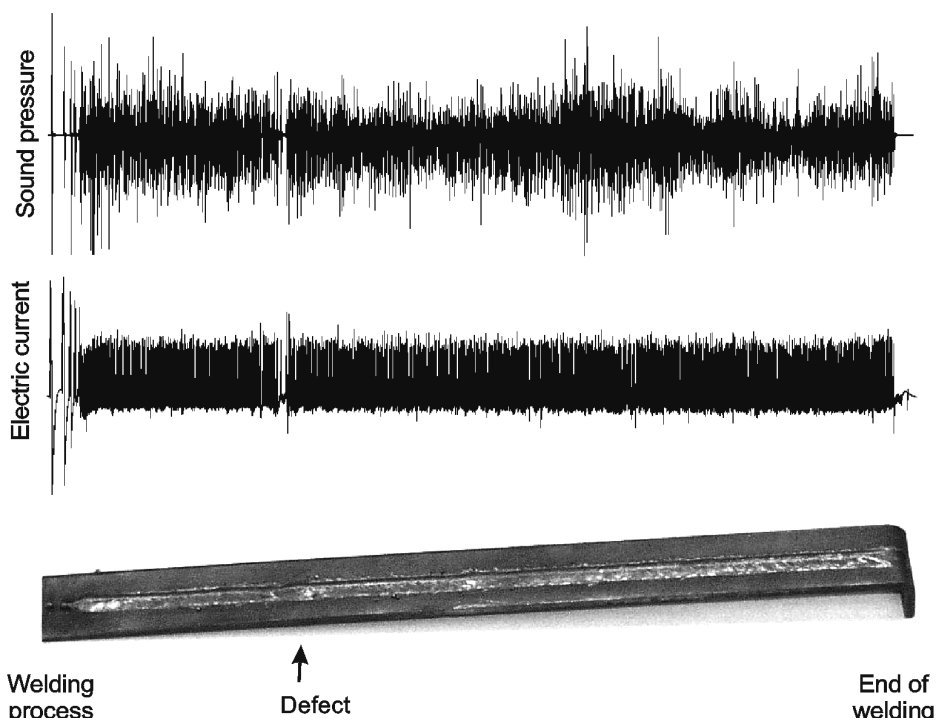

Fig. 10. Specimen of heated steel with detail of the welding defect
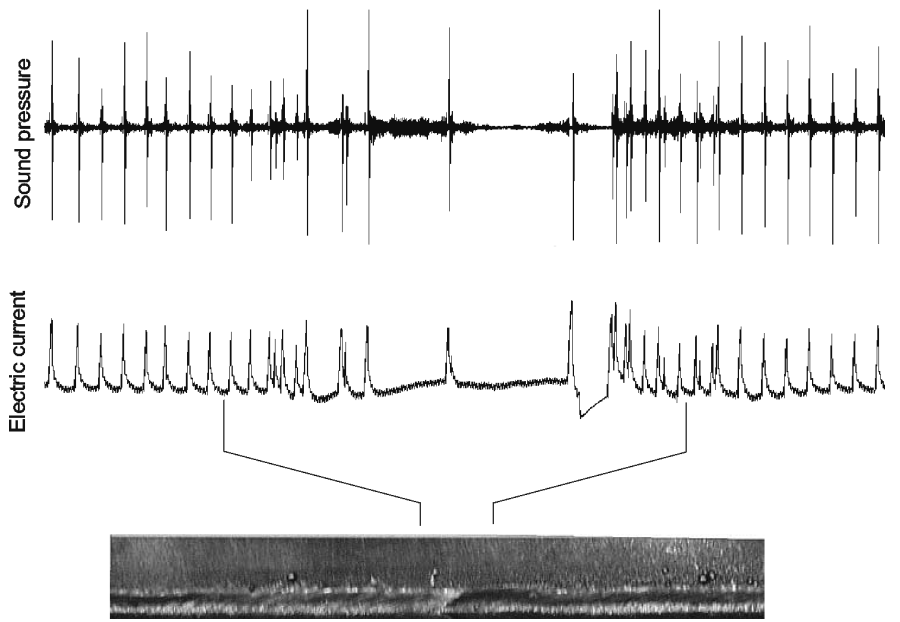

Fig. 11. Enlargement of defect in welding process with the records of welding current and corresponding sound pressure for structural steel 
total noise level and then to assess the effect of the welding noise on the worker.

The main advantage of the proposed algorithm, based on the current welding data, is that the calculated values are not corrupted by background and reverberation noise as is in the case of measuring noise in an industrial environment. Determination of welding noise using the proposed algorithm is thus more exact, robust and user-friendly.

Some measurements made in a metal (industrial) environment, without important secondary sources, have shown that A-weighted sound pressure level can reach and even exceed $100 \mathrm{~dB}$ at the welder's ear, see Table 1. In Table 1 , characteristic measured parameters of noise (peak noise, equivalent noise and impulse noise) at welding of construction steel IPE-400 profiles, measured by a precise sound pressure analyzer, B\&K, Type 2260, are presented.

This means that the noise can affect the worker's health since daily A-weighted equivalent sound pressure level from approximately 65 to 85 $\mathrm{dB}$ causes an acoustic trauma, whereas the sound pressure level above $85 \mathrm{~dB}$, and especially above $90 \mathrm{~dB}$, can cause hearing damage.

\section{CONCLUSIONS}

During the GMAW process noise emission can rise above the welder daily permissible A-weighted sound pressure level of $80 \mathrm{~dB}(\mathrm{~A})$. Therefore, theoretical and experimental analyses of the sound signal were performed, examining both time and frequency, in order to find the sound origin in time and space. Analyses have shown that the sound spectra of the welding process are broadband with pronounced peaks at higher frequencies (above $5 \mathrm{kHz}$ ). There are two mechanisms that generate the overall noise during the welding process: impulse noise and the so-called "turbulent" noise. The impulse noise has its origin in short circuit arc extinction and arc ignition, and the turbulent noise has different origins; the most important are: oscillation of the arc, the electrode and the molten pool, as well as racking of the material due to inner tension relaxation. The impulse noise is far more than $10 \mathrm{~dB}$ higher then the turbulent noise and thus represents the dominant noise generating mechanism during the welding process. A new algorithm for calculation of sound generated during welding process was established. The algorithm represents a transfer function between the welding current and emitted sound pressure. The algorithm was verified on different welded materials (structural steel and heated steel). Comparisons have shown that the calculated values are in good agreement with the measured results. The main advantage of the proposed algorithm based on the current welding data, is that the calculated values are not influenced or corrupted by background and reverberation noise as it is in a case of noise measurement in industrial environment. Therefore, it is also suitable for online monitoring and control of welding process stability and quality.

\section{REFERENCES}

[1] Saini, D., Floyd, S. (1998). An investigation of gas metal arc welding sound signature for on-line quality control. Welding Journal, vol. 77, no. 4, p. 172s -179s.

[2] Choi, J.H., Lee, J.Y., Yoo, C.D. (2001). Simulation of dynamic behaviour in a GMAW System. Welding Journal, vol. 80, no. 10 , p. 239s-245s.

[3] Erdmann-Jesnitzer, F., Feustel, E., Rehfeldt, D. (1967). Akustische Untersuchungen am Schweislichtbogen. Schw. und Schn., vol. 19, no. 3, p. 95-100.

[4] Jolly, W.D. (1969). Acoustic emission exposes cracks during welding. Welding Journal, vol. 48, no. 1, p. 21-27.

[5] Arata, Y. (1979). Investigation on welding arc sound. Report 1, IIW Doc.S. G.212-451-79.

[6] Mayer, J.L. (1987). Application of acoustic emission to in process monitoring of submerged arc welding. IIW Doc V-WG329-87.

[7] Rostek, W. (1990). Investigations on the connection between the welding process and airborne noise emission in gas shielded metal arc welding. Schw. und Schn., vol. 42, no. 6, p. E96-E97.

[8] Grad, L., Kralj, V. (1996). On line monitoring of arc welding process using acoustic signals. Proc. of the $13^{\text {th }}$ Conference BIAM '96, Zagreb. 
[9] Morris, R.A., Tate, R.C., Matteson, M.A. (1994). Weld Acoustic Monitor, US Patent, No. 5,306,893.

[10] Ravnik, F., Grum, J. (2009). Sound emitted at boundary layer during steel quenching. Strojniški vestnik - Journal of Mechanical Engineering, vol. 55, no. 3, p. 199-211.

[11] Kim, J.S., Eagar, T.W. (1993). Metal transfer in pulsed current gas metal arc welding, Welding Journal, vol. 72, no. 7, p. 279-284.

[12] Ogukbiyi, B., Nixon, J., Richardson, I., Blackman S. (1999). Monitoring indices for assessing pulsed gas metal arc welding process. Science and Technology of Welding and Joining, vol. 4, no. 4, p. 209-213.

[13] Morita, T., Ogawa, Y., Sumitomo, T. (1995). Analysis of acoustics signals on welding and cutting, Materials Engineering, ASME, vol. III.

[14] Polajnar, I., Prezelj, J., Čudina, M. (2006). Comparison of sound pressure level generated in an authomatized MIG/MAG and resistance spot welding, Varilna tehnika, vol. 56 no. 2, p. 61-69. (in Slovene)

[15] Dadgar, H., Pilorget, A., Fitaire, M. (1977). Acoustic noise excited by electric arc. IEEE International Conference on Plasma Science: Conference record - Abstracts, R. PI., p. 117.

[16] Mansoor, A.M., Huisson J.P. (1999). Acoustics identification of GMAW process. Special publication of the $9^{\text {th }}$ international conference on computer technology in welding, p. 312-323.

[17] Drouet, M., Nadeau, F. (1982). Acoustic measurement of the arc voltage applicable to arc welding and arc furnaces. Journal of Physics E: Scientific Instruments, vol. 15, no. 3, p. 268 - 269.

[18] Grad, L., Prezelj, J., Polajnar, I., Grum, J. (2001). Welding process assessment by analyzing on line measured acoustic signals. Proceedings of the $6^{\text {th }}$ International Conference of the Slovenian Society for NonDestructive Testing, Portorož, p. 185-189.

[19] Čudina, M., Prezelj, J., Polajnar, I. (2008). Use of audible sound for on-line monitoring of gas metal arc welding process. Metallurgy, vol. 47 , no. 2 , p. 81-85.

[20] Manz, A.F. (1981). Welding arc sound. Welding Journal, vol. 60, no. 5, p. 23-27.

[21] Polajnar, I., Prezelj, J., Mišina, N., Čudina, M. (2007). Noise on the working place of a welder. Sigurnost, vol. 49, no. 2, p. 113-124. (In Croatian)

[22] Horvat, J., Polajnar, I., Čudina, M., Dahmane, R. (2007). Ergonomic stresses of welders. Strojarstvo, vol. 49, no. 5, p. 377382.

[23] Grum, J., Gorkič, A., Kejžar, R., Polajnar I. (2007). Influence of the type of workpiece adjustment and energy input on the quality of a RPW. Int. j. mater. prod. technol., vol. 29 , no. $1 / 2 / 3 / 4$, p. 272-296. 